\title{
Hydrogen embrittlement risk of high strength galvanized steel in contact with alkaline media
}

\author{
F.J. Recio ${ }^{\mathrm{a}}$, M.C. Alonso ${ }^{\mathrm{a}, *}$ L. Gaillet $^{\mathrm{b}}{ }$, M. Sánchez ${ }^{\mathrm{a}}$ \\ ${ }^{a}$ CISDEM, Research Centre for Security and Durability of Structures and Materials (UPM-CSIC), Madrid, Spain \\ ${ }^{\mathrm{b}}$ Laboratoire Central des Ponts et Chaussées (LCPC), Nantes, France
}

Keywords:

A. Steel reinforced concrete

A. Zinc

C. Hydrogen embrittlement

\begin{abstract}
A B S T R A C T
The critical conditions for hydrogen embrittlement (HE) risk of high strength galvanized steel (HSGS) wires and tendons exposed to alkaline concrete pore solutions have been evaluated by means of electrochemical and mechanical testing.

There is a relationship between the hydrogen embrittlement risk in HSGS and the length of hydrogen evolution process in alkaline media. The galvanized steel suffers anodic dissolution simultaneously to the hydrogen evolution which does not stop until the passivation process is completed. HSGS wires exposed to a very high alkaline media have showed HE risk with loss in mechanical properties only if long periods with hydrogen evolution process take place with a simultaneous intensive galvanized coating reduction.
\end{abstract}

\section{Introduction}

The use of galvanized steel tendons in prestressing structures is restricted to external application of non-adherent type. The reason to this limitation is the possibility of failure due to risk of hydrogen embrittlement of the bare steel that can arise when loaded galvanized tendons or wires are in direct contact with high alkaline cement based materials. However, there are insufficient evidences to this restriction that claim for a deeper investigation [1-8].

The effectiveness of hot-dip galvanizing to improve corrosion resistance of steel has been widely studied in aggressive environments and because numerous papers have been published about it, including real applications, nowadays the method is recognized as an effective protection measure for reinforcement corrosion [9-12].

The galvanized reinforcement shows a temporary instability associated to the contact of the $\mathrm{Zn}$ with a fresh alkaline concrete matrix. The reason for this is the high $\mathrm{pH}$ of the aqueous phase contained in the pores of the concrete that usually varies between 12.5 and 13.5. In this typical range of $\mathrm{pH}$ the $\mathrm{Zn}$ is oxidized, and the cathodic reaction arisen from water hydrolysis with hydrogen evolution takes place on the galvanized surface [13-18]. The global process can be described as:

$\mathrm{Zn}+2 \mathrm{H}_{2} \mathrm{O} \rightarrow \mathrm{Zn}(\mathrm{OH})_{2}+\mathrm{H}_{2}(\mathrm{~g})$

\footnotetext{
* Corresponding author. Tel.: +34 91 3020440; fax: +34 913020700.

E-mail addresses: mcalonso@ietcc.csic.es, mcalonso@cisdem.upm-csic.es (M.C. Alonso).
}

The specific problem of hydrogen embrittlement risk in prestressing galvanized tendons was first studied by Riecke [3], who proposed a mechanism to understand the phenomena occurring in alkaline media:

Anodic dissolution of zinc $: \mathrm{Zn} \rightarrow \mathrm{Zn}_{2}^{+}+2 \mathrm{e}^{-}$

Cathodic reaction from water hydrolysis : $2 \mathrm{H}^{+}+2 \mathrm{e}^{-} \rightarrow \mathrm{H}_{2}(\mathrm{~g}) \uparrow$

The proton generated in the cathodic reaction is the agent that could induce hydrogen embrittlement of the steel according with the next sequence of reactions [3].

$\mathrm{H}^{+}+\mathrm{e}^{-} \rightarrow \mathrm{H}_{\mathrm{ad}}$

$\mathrm{H}_{\mathrm{ad}}+\mathrm{H}_{\mathrm{ad}} \rightarrow \mathrm{H}_{2} \uparrow$

$\mathrm{H}_{2} \mathrm{O}+\mathrm{H}_{\mathrm{ad}}+\mathrm{e}^{-} \rightarrow \mathrm{H}_{2} \uparrow+\mathrm{OH}^{-}$

$2 \mathrm{H}_{\mathrm{ad}}+1 / 2 \mathrm{O}_{2} \rightarrow \mathrm{H}_{2} \mathrm{O}$

$\mathrm{H}_{\mathrm{ad}} \rightarrow \mathrm{H}_{\mathrm{ab}}$

Only the reaction (8) increases the risk to induce hydrogen embrittlement in galvanized prestressing steel. The atoms of hydrogen generated at the level of the cement paste-galvanized coating interface can be absorbed and can diffuse through the thickness of the galvanized coating towards the bare steel by bulk or short-circuits diffusion paths.

The hydrogen embrittlement susceptibility of prestressing steel is attributed to the ability that the atoms of hydrogen formed in the corrosion process result absorbed in the Fe-C lattice (reversible 
diffusion) or trapped by defects present in the steel microstructure (grain boundaries, dislocation piles-up) and in the metal lattice. This last process induces hydrogen embrittlement risk by a degradation mechanism that can deform the metal lattice [19]. As the amount of hydrogen trapped in the steel increases, also does the level of embrittlement.

The length and intensity of the hydrogen evolution period on galvanized steel in the alkaline environment generated by the cementitious material is limited by the alkaline environment composition itself and the creation of a passive layer. The formation of this passive layer in cement alkaline media was first described by Lieber [20] through the mechanism given in Eqs. (1) \& (9) where the $\mathrm{Ca}$ content in the alkaline pore media plays a key role:

$\mathrm{Zn}(\mathrm{OH})_{2}+2 \mathrm{H}_{2} \mathrm{O}+\mathrm{Ca}(\mathrm{OH})_{2} \rightarrow \mathrm{Ca}\left(\mathrm{Zn}(\mathrm{OH})_{3}\right)_{2} \cdot 2 \mathrm{H}_{2} \mathrm{O}$

The generation rate and the efficiency of the passive layer formed, basically constituted by calciumhydroxizincate $\mathrm{Ca}(\mathrm{Zn}$ $\left.(\mathrm{OH})_{3}\right)_{2} \cdot 2 \mathrm{H}_{2} \mathrm{O}$, (CaHZ crystals) is function of the $\mathrm{pH}$ of the alkaline media, and more specifically is determined by the proportion of calcium ions in the pore solution [21].

Although these processes are well accepted for galvanized reinforcement, there is a lack of knowledge when considering the case for galvanized prestressing steel and the hydrogen embrittlement of the bare steel. The aim of this study is to assess this risk of hydrogen embrittlement of galvanized steel tendons and wires under service load conditions (80\% Ultimate Tension Stress, UTS) in alkaline environments containing $\mathrm{Ca}$. The influence of the $\mathrm{pH}$ in the surrounding environment and the duration of the hydrogen evolution process on galvanized steel are considered and changes in the mechanical parameters are evaluated.

\section{Experimental}

Two kind of commercial High Strength Galvanized Steels (HSGS) presented as individual prestressing wires or as full tendons were used. The bare wire was an eutectoid steel with a chemical composition (in atom $\%$ ) of: $\% \mathrm{C}=0.8, \% \mathrm{Si}=0.2, \% \mathrm{Mn}=0.7$, $\% \mathrm{~S}<0.03$ and $\% \mathrm{P}<0.02$. The parent steel was first submitted to a cold drawing process for high strength mechanical properties of the roll wire. The cold drawn wire was then galvanized by immersion in a continuous process inside a hot dip Zinc bath at $450{ }^{\circ} \mathrm{C}$ for $8-10 \mathrm{~s}$ to allow the intermetallic galvanized coatings to grow on the surface of the steel wire but guaranteeing no losses of the high mechanical properties. The cooling process varies in function of the patented method used by the producer. The HSGS identified as G1 was an individual wire of $5 \mathrm{~mm}$ diameter provided as a rod. The other galvanized steel, G2, was provided as a tendon and was composed by seven wires of $5 \mathrm{~mm}$ diameter (six helicoidally wires around a straight central one).

Longitudinal and transverse samples of both galvanized steels were cut in order to study the characteristics of the galvanized coating like the variation of the coating thickness, the microstructure and the chemical composition. The samples were embedded in a resin, abraded with emery papers from grade 120 to 600 and finally polished with diamond cloths of $3 \mu \mathrm{m}$. The polished surfaces were etched with $\mathrm{Nital}\left(2 \% \mathrm{HNO}_{3}\right.$ in $\left.\mathrm{EtOH}\right)$ and its microstructure was identified using optic and SEM microscopy. The composition was determined with EDAX probe coupled to the SEM. The galvanized sub-layers thicknesses were determined using the Metreo Program coupled with a metallographic microscope.

The corrosion tests were performed in polypropylene containers stable in high alkaline environments. The shape of the cells was different according to the length of the samples and the type of test. The tests were carried out without applying external mechanical load to the samples or by applying a load of $80 \%$
(UTS). The later (80\%UTS) was chosen in order to simulate the real stress level of prestressed concrete structures. G1 wires and G2 tendons were used as working electrodes and the exposure area was $1.57 \mathrm{~cm}^{2}$ for $\mathrm{G} 1$ wires and $15.7 \mathrm{~cm}^{2}$ for $\mathrm{G} 2$ tendons. A stainless steel mesh was used as counter electrode and a saturated calomel electrode (SCE) as reference. The tests were performed in alkaline solutions with a pH from 12.5 to 13.5 in order to simulate the concrete pore solution. The solutions were made by addition of alkalis like $\mathrm{NaOH}$ and $\mathrm{KOH}$ to a mother solution of saturated $\mathrm{Ca}(\mathrm{OH})_{2}$ :

\begin{tabular}{|c|c|c|}
\hline 1. & $\mathrm{Ca}(\mathrm{OH})_{2}$ sat. & $\mathrm{pH}_{25^{\circ} \mathrm{C}}=12.5$ \\
\hline 2. & $\mathrm{Ca}(\mathrm{OH})_{2}$ sat. + NaOH $0.1 \mathrm{M}$ & $\mathrm{pH}_{25^{\circ} \mathrm{C}}=12.8$ \\
\hline 3. & $\mathrm{Ca}(\mathrm{OH})_{2}$ sat. $+\mathrm{KOH} 0.2 \mathrm{M}$ & $\mathrm{pH}_{25^{\circ} \mathrm{C}}=13.2$ \\
\hline 4. & $\mathrm{Ca}(\mathrm{OH})_{2}$ sat. $+\mathrm{KOH} 0.5 \mathrm{M}$ & $\mathrm{pH}_{25^{\circ} \mathrm{C}}=13.5$ \\
\hline
\end{tabular}

The corrosion potential $\left(E_{\text {corr }}\right)$ and the polarization resistance $\left(R_{\mathrm{P}}\right)$ were measured periodically throughout the test. The current density $\left(i_{\text {corr }}\right)$ was calculated using the Stern-Geary relation: $i_{\text {corr }}=B / R_{P}$, where $B$ is a constant that varies with the type of steel and environment. In present case a mean value of $B=26 \mathrm{mV}$ ( $59 \mathrm{mV} /$ decade) was selected. This $B$ value was considered according to previous papers $[22,23]$ and from Tafel slopes determination [24] for galvanized steel reinforcements immersed in alkaline solution of similar $\mathrm{pH}$ than those used in present paper.

The accumulated hydrogen inside the high strength galvanized steel was determined with a non standard method developed by Gaillet [25]. After the exposure to the hydrogen source inside the alkaline media the galvanized steel samples were immersed in a mercury bath at room temperature. Hydrogen accumulated inside the metal, spontaneously diffuses out of the steel wire and the gas is collected in a device placed at the top of the mercury bath, in absence of air.

Two mechanical test protocols were followed in order to determine the influence of hydrogen generation process in the mechanical properties of HSGS. The tests were carried out in galvanized wires and tendons:

(1) Constant load + Tensile Test of the samples (TT): During this test procedure, G1 and G2 HSGS wires and tendons were loaded at $80 \%$ of UTS according to in situ conditions of concrete prestressed structures and exposed to different alkaline media in order to reproduce different hydrogen evolution lengths. The alkaline solution was removed and a mechanical test was performed at a velocity of $5 \mathrm{MPa} /$ min. For reproducibility assessment of the phenomena, three G1 wires were tested in each testing conditions so mean values could be obtained.

(2) Constant load + Slow Strain Rate Test of samples (SSRT): This test procedure was carried out in tendon G2, previously loaded at $80 \%$ UTS and exposed to a solution of $\mathrm{pH} 13.5$ over a period of 6,24 and $48 \mathrm{~h}$ of having different length of the hydrogen evolution process. Once the exposure time finished, the tendons were tested by SSRT (strain rate $=$ $10^{-7} \mathrm{~s}^{-1}$ ) inside the alkaline environment.

After mechanical test, a SEM study of the fracture surfaces was performed when brittle damage was detected in order to observe microstructure fracture regions associated to hydrogen embrittlement.

\section{Results and discussion}

\subsection{Galvanized coating properties}

The thickness of the galvanized coating and its microstructure have a relevant role in the corrosion performance of galvanized 
reinforcement in alkaline environments, both in passivation and corrosion processes $[10,13,17]$. For HSGS steel this is an aspect of particular concern due to the risk of hydrogen embrittlement. SEM and metallographic images of the G1 and G2 galvanized coatings are shown in Fig. 1. The chemical composition, the structure and thickness of the total galvanized coating and of the sub-layers were determined.

It can be observed that the galvanized coating microstructure is formed by the typical sub-layers of conventional hot-dip galvanized steel [26-29]. The chemical composition and the morphology of the sub-layers allow to identify not only the presence of an external pure $\mathrm{Zn}$ layer $(\eta)$ but also the internal sub-layers, $\gamma$ and $\delta$, that contain progressive increase of Fe content towards the inner in the alloy. Table 1 compiles the chemical composition and thickness variation of the different sub-layers.

According with the experimental values obtained, the galvanized coating of both G1 and G2 show a high thickness variability, being the external pure $\mathrm{Zn}$-layer which shows the highest dispersion, closely associated with the cooling process employed. The mean coating thickness values determined for the galvanized coatings are $33 \pm 6 \mu \mathrm{m}$ for $\mathrm{G} 1$ and $41 \pm 4 \mu \mathrm{m}$ for G2, respectively. The maximum thickness was respectively 41 and $50 \mu \mathrm{m}$. However, a smaller total thickness of $10-15 \mu \mathrm{m}$ was also measured in local zones of the galvanized coating. These local low coating thicknesses have a high importance for the further performance of the HSGS under hydrogen evolution process in the alkaline environment. The mechanical properties were characterized in $G 1$ and $\mathrm{G} 2$ individual wires and in G2 tendon. Table 2 shows the values obtained for both materials, showing that all fulfil, after the galvanized process, the mechanical requirement $\left(\sigma_{\max }>1700 \mathrm{MPa}\right)$ for prestressed wires.

\subsection{Influence of the $\mathrm{pH}$ media in the corrosion process during hydrogen evolution}

Hydrogen evolution process in unloaded and loaded galvanized wires at $80 \%$ UTS exposed in several alkaline media were identified by means of the analysis of corrosion potential $\left(E_{\mathrm{corr}}\right)$ and of corrosion current density $\left(i_{\text {corr }}\right)$ measures. Fig. 2 shows the $E_{\text {corr }}$ and $i_{\text {corr }}$ evolutions in G1 wires.

Soon after galvanized wires enter in contact with the alkaline environment, cathodic polarization of the galvanized steel is detected reaching lower potentials than $-1000 \mathrm{mV} / \mathrm{SCE}$ which indicate a hydrogen evolution process taking place on the surface of the galvanized steel $[15,18,21,24]$. The end of the hydrogen evolution period is easily identified due to the rise up of the corrosion potential to values around $-600 \mathrm{mV} / \mathrm{SCE}$. In the lower $\mathrm{pH}$ media, the hydrogen evolution process finishes before the $5 \pm 2 \mathrm{~h}$ of experiment. In wires exposed to $\mathrm{pH} 13.2$, the hydrogen evolution process
Table 1

Chemical analysis and thickness of galvanized coatings. Sub-layer characterization.

\begin{tabular}{|c|c|c|c|c|}
\hline \multirow[t]{2}{*}{ Sub-layer } & \multicolumn{2}{|c|}{$\begin{array}{l}\text { Chemical composition (atom\% Zn/ } \\
\text { Fe) }\end{array}$} & \multicolumn{2}{|c|}{ Thickness coating ( $\mu \mathrm{m})$} \\
\hline & G1 & G2 & G1 & G2 \\
\hline$\delta$ & $90.6 / 9.6$ & $90.7 / 9.2$ & $5.87 \pm 1.38$ & $6.28 \pm 0.93$ \\
\hline$\gamma$ & $93.3 / 6.6$ & $93.2 / 6.7$ & $13.05 \pm 2.73$ & $13.61 \pm 3.47$ \\
\hline$\eta$ & $99.4 / 0.5$ & $99.6 / 0.4$ & $21.75 \pm 4.97$ & $14.74 \pm 6.13$ \\
\hline
\end{tabular}

Table 2

Mechanical properties in $\mathrm{G} 1$ wires and $\mathrm{G} 2$ wires and tendons.

\begin{tabular}{llll}
\hline & Max. stress (MPa) & Yield point (MPa) & Strain (\%) \\
\hline Wire G1 & 2127 & 1962 & 3.1 \\
Tendon G2 & 1860 & 1653 & 3.5 \\
Wire G2 & 1954 & 1792 & 4.2 \\
\hline
\end{tabular}

is delayed by $35 \pm 5 \mathrm{~h}$ and in wires exposed at $\mathrm{pH} 13.5$ the hydrogen evolution does not stop during the $48 \mathrm{~h}$ of testing.

Similar information can be deduced from the $i_{\text {corr }}$ results, During the hydrogen evolution period, the wires show maximum $i_{\text {corr }}$ values around $100 \mu \mathrm{A} / \mathrm{cm}^{2}$, and when the hydrogen evolution process finishes and the passive layer is formed, the $i_{\text {corr }}$ drops two orders of magnitude at values of around $1 \mu \mathrm{A} / \mathrm{cm}^{2}$. This behavior is directly related to the amount of $\mathrm{Ca}^{2+}$ ions present in the alkaline environment that participate in the formation of $\mathrm{CaHZ}$ crystals forming the passive layer on the surface of the galvanized steel. The $\mathrm{Ca}$ content decreases with the increase of $\mathrm{pH}$ which makes the passivation more difficult to occur. Similar trend was found in the response of galvanized coatings of reinforcement [17,30-32].

The effect of the stress level in the steel can also be observed in the Fig. 2. While the wires stressed and exposed to $\mathrm{pH} 12.5$ and 12.8 do not show differences compared to not-stressed wires, the wires exposed to $\mathrm{pH} 13.2$ (therefore $\mathrm{Ca}^{2+}$ concentration drops) an extension of the end of the hydrogen evolution process and the start of the passivation stage is detected. This delay could be associated to the generation of microcraks defects induced in the galvanized coating by the stress applied [33]. This presence of microcracks would increase the $\mathrm{Zn}$ and $\mathrm{Zn} / \mathrm{Fe}$ area exposed to the alkaline media, intensifying the $\mathrm{Zn}$ dissolution and retarding passivation of the galvanized steel. Further on, these micro-cracks could facilitate the absorption and penetration (shortening diffusion paths) of the hydrogen generated in the corrosion process into the galvanized coating.

The $E_{\text {corr }}$ and $i_{\text {corr }}$ were also carried out in tendons and similar trends with the $\mathrm{pH}$ were found, although more deviation in the length of the hydrogen evolution period was detected. This
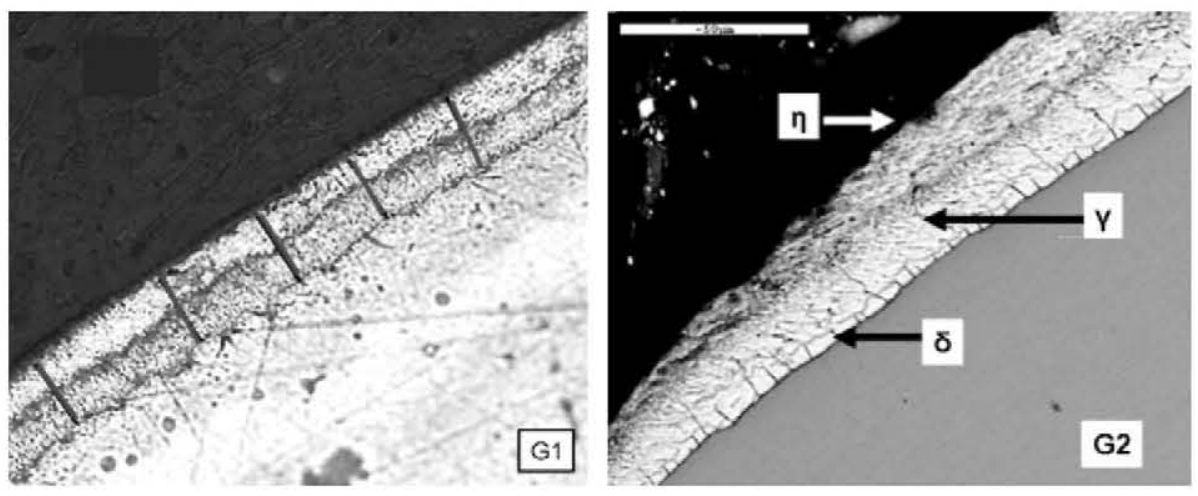

Fig. 1. Thickness measurements using optic microscope of the galvanized coating G1 (left) and sub-layers identification on a SEM image galvanized coating G2 (right). 


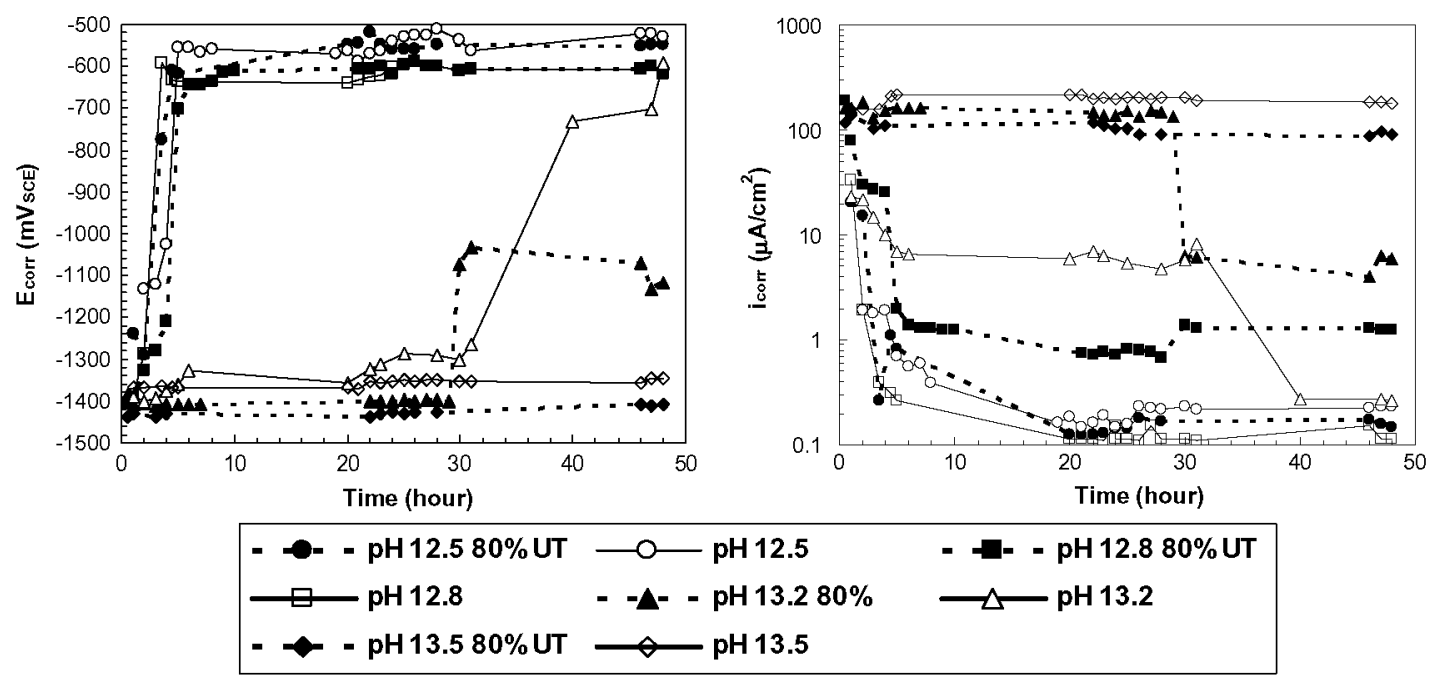

Fig. 2. $E_{\text {corr }}$ (left) and $i_{\text {corr }}$ (right) measurements in G1 wires (unloaded, full lines and loaded at $80 \%$ UTS, dashed lines) exposed to the alkaline media.

deviation can be associated to the different geometry of the tendons which could difficult the total passivation of the galvanized surface.

The $i_{\text {corr }}$ generated during the test can be related to the anodic dissolution of the $\mathrm{Zn}$ by means of the Faraday law. The loss of galvanized coating has been calculated considering a general and homogeneous corrosion of the galvanized coating as Fig. 3 shows.

This approach is accurate enough in most cases, although some authors [32,34] suggest a more heterogeneous corrosion of the galvanized coating in reinforcements at higher pHs. In the HSGS studied, the corrosion of the galvanized coating has shown to be more concentrated in small areas inducing local losses of the galvanized coating as shows the Fig 4 in which local regions with higher dissolution can be observed and even the total loss of the external $\eta$ sub-layer of pure $\mathrm{Zn}$ can be clearly identified.

Although the global corrosion process until passivation of the galvanized steel in the alkaline media follows an exponential trend, two individual processes can be easily identified by showing different slopes from Fig 3. In the first stage, the slope is high which indicates that the dissolution of the external $\mathrm{Zn}$ layer $(\eta)$ is very active and takes place simultaneously to the hydrogen evolution process. The second stage is identified by the decay in the slope (trend to zero) indicating that the hydrogen evolution process has finished and the passive layer is being generated. The reason is attributed to the formation of $\mathrm{CaHZ}$ crystals and their deposition on the surface of the galvanized steel that allows isolation of the $\mathrm{Zn}$ from the alkaline environment. The ability to generate $\mathrm{CaHZ}$ crystals in the environment is fundamental in this stage, as it stops the hydrogen evolution and passivates the galvanized steel. The models to explain the corrosion differences at different pHs previously reported
$[17,21,22,30-32]$, are based on the $\mathrm{Ca}^{2+}$ saturated media and on the concrete pores. In this respect, the evolution of cement hydration during first hours and changes in the pore solution composition are vital [35]. Initially the pore solution owns high contents of $\mathrm{Ca}^{2+}$ dissolved, that decreases with the advance of setting and cement hydration, with an increase in the $\mathrm{pH}$. This process varies with the amount and type of cement.

After $48 \mathrm{~h}$ the coating loss estimated at $\mathrm{pH} 13.5$ (the hydrogen evolution and the active corrosion of $\mathrm{Zn}$ extends throughout the whole duration of test) shows a maximum mean value of $10 \mu \mathrm{m}$ (see Fig. 3) that, according to Fig. 4, can be associated to the total loss of the external pure $\mathrm{Zn}$ layer in some specific regions of the galvanized coating. The thickness of the external $\eta$-coating of pure $\mathrm{Zn}$ varies from 20 to $10 \mu \mathrm{m}$ (given in Table 1), so during hydrogen period the total loss of the external $\mathrm{Zn}$ layer may occur in this aggressive alkaline environment. The $\mathrm{Zn}$ layer $\eta$, is considered to have more resistance to hydrogen transport [36] to that showed by the steel, so the simultaneous reduction of the galvanized coating during hydrogen period will favor the hydrogen diffusion inside the galvanized steel, particularly in very alkaline environments and long hydrogen evolution periods as mechanical results will confirm later.

\subsection{Detection of hydrogen inside the galvanized steels}

In order to detect the presence of hydrogen inside the galvanized steels wires, G2 tendons were subjected to 80\%UTS and exposed to alkaline media. The tendons were removed from the alkaline media after $48 \mathrm{~h}$ of exposition to the aggressive media, soon after a piece of each wire directly exposed to each alkaline

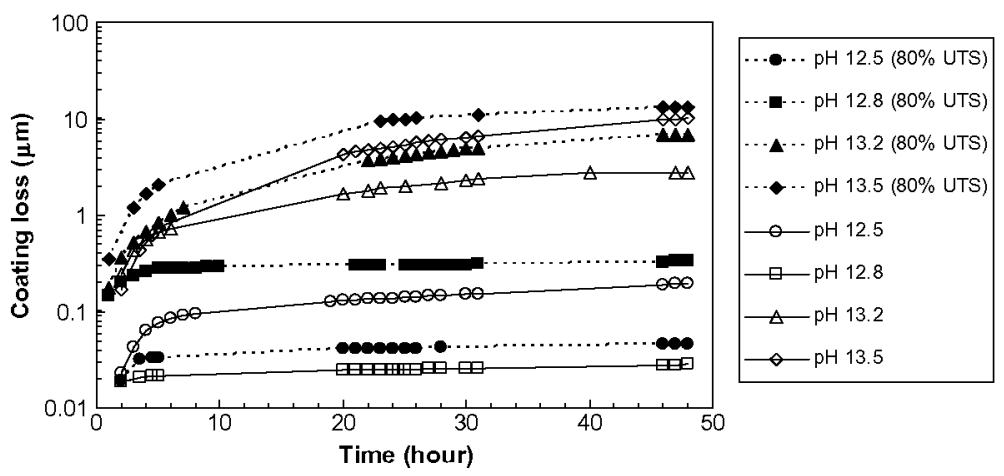

Fig. 3. Galvanized coating loss from $i_{\text {corr }}$ measurements in $\mathrm{G} 1$ wires over $48 \mathrm{~h}$ in different alkaline and load conditions. 

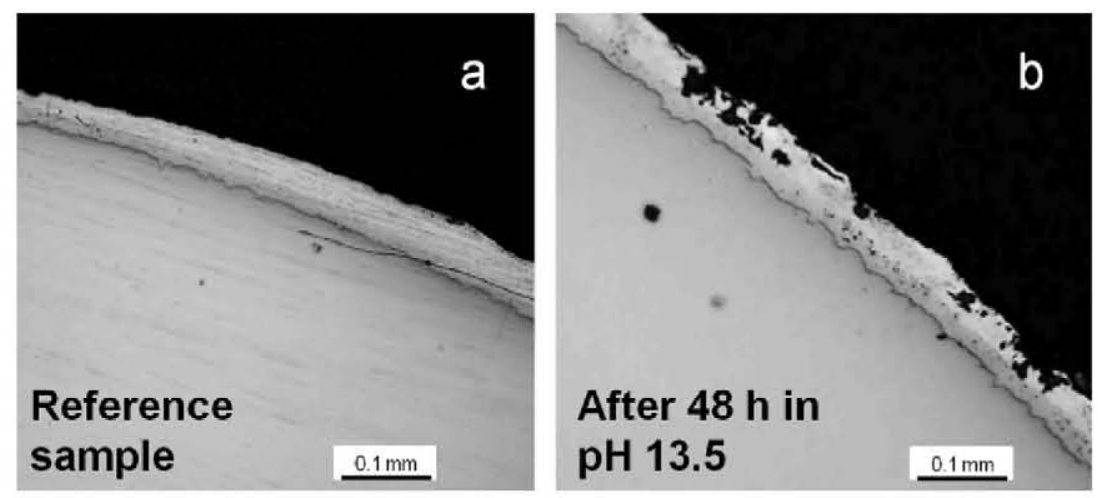

Fig. 4. Galvanized layer of G1 wire. (a) Reference case, without immersion in any media, (b) After $48 \mathrm{~h}$ of immersion in the alkaline solution pH 13.5 .

media was cut out from the tendon and immersed in the mercury bath to determine the hydrogen accumulated, expressed by $\mathrm{ml} /$ $100 \mathrm{~g}$ of steel. The values of hydrogen accumulated are represented in Fig. 5. The lengths of the hydrogen evolution process in the tendons founds were: $4 \mathrm{~h}$ for the $\mathrm{pH} 12.5,12 \mathrm{~h}$ for the $\mathrm{pH} 12.8$ and $48 \mathrm{~h}$ for the $\mathrm{pH}$ 13.5. The initial amount of hydrogen determined in HSGS wires not exposed to alkaline media were determined and used as reference $(0.5 \mathrm{ml} / 100 \mathrm{~g})$.

The penetration of hydrogen in the galvanized steel after $48 \mathrm{~h}$ exposed at several $\mathrm{pH}$ media was confirmed, as shown in Fig. 5. The values obtained are directly related with the length of the hydrogen evolution process. The amount of hydrogen accumulated in the metal is higher as the $\mathrm{pH}$ increases. The increase in corrosion activity and length of hydrogen evolution process (delay in the passivation stage) induces an increase in the volume of hydrogen accumulated inside the steel. The loss of galvanized coating during hydrogen evolution period plays an important role in the penetration and accumulation of atomic hydrogen inside the steel. The $\mathrm{Zn}$ coating acts as a barrier against hydrogen penetration and diffusion retaining hydrogen in its crystal structure due to the interstitial spaces in the hexagonal $\mathrm{Zn}$ lattice [36]. The progressive oxidation of the $\mathrm{Zn}$ coating reduces the thickness of the galvanized coating and finally allows the penetration of atomic hydrogen to the bare steel.

Similar diffusion response of hydrogen release has been found in the literature [25] using the same detection method for prestressing carbon steel previously charged with hydrogen by cathodic polarization. The hydrogen accumulation content obtained by this method was lower than the one using other methods; this is because in the mercury bath procedure only the free diffusible hydrogen is determined but not the hydrogen trapped or occluded in the iron lattice that can only be removed using more aggressive methods, as heating [34].

\subsection{Mechanical properties determination}

Mechanical properties of individual wires and full tendons exposed at $80 \%$ UTS to the different alkaline media during $48 \mathrm{~h}$ were determined by TT tests. The results show different performance depending on the $\mathrm{pH}$ of the environment. Fig. 6 shows an example of the strain-stress curves obtained at several alkaline media.

The mechanical properties of wires exposed in aggressive media during $48 \mathrm{~h}$ show a clear trend: when $\mathrm{pH}$ media increases the mechanical properties are reduced. That is, there is a direct relationship between the lengths of the hydrogen evolution process with the reduction of the mechanical properties.

Fig. 7 summarizes the results obtained in mechanical tests where the relative cross section reductions of wires are compared with the $\mathrm{pH}$ of the aggressive media. The horizontal dash line which appears in Fig. 7 corresponds to the cross section of the steel before exposure to alkaline media. A reduction of the cross section under the reference values has been taken as indicative of the hydrogen embrittlement process. According to this, only wires

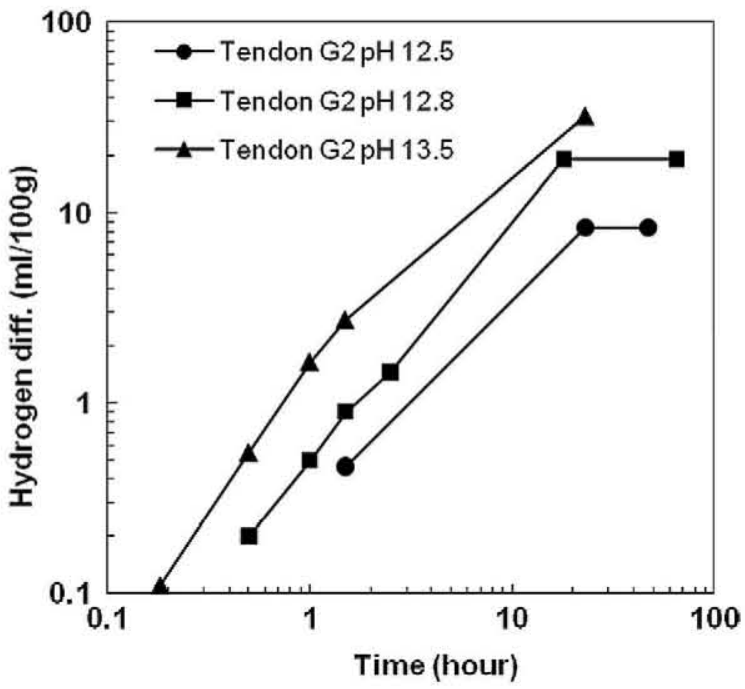

Fig. 5. Hydrogen accumulated in galvanized tendon $G 2$ after exposure to several alkaline $\mathrm{pH}$.

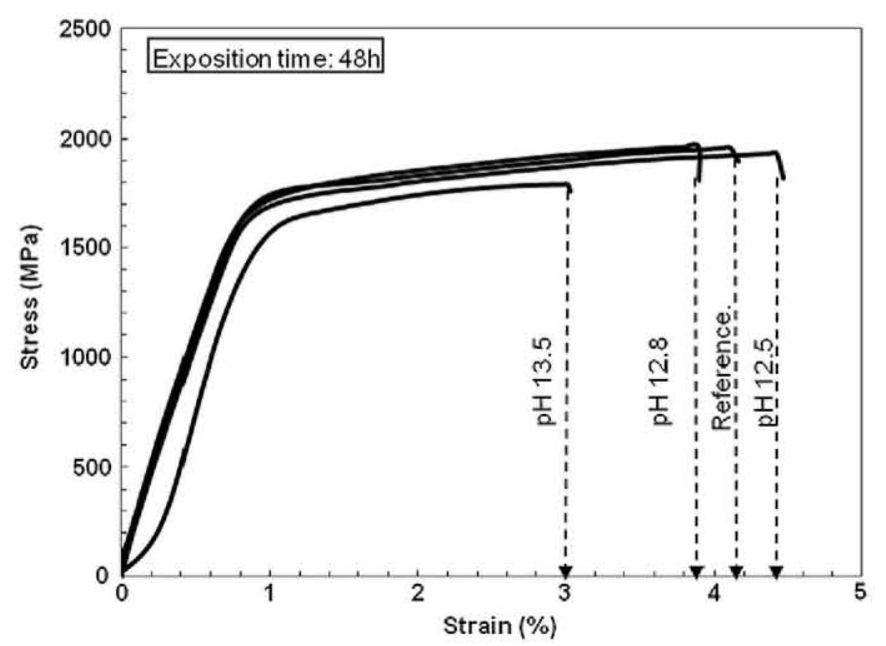

Fig. 6. Stress-Strain curves of individual galvanised wire $G 2$ after $48 \mathrm{~h}$ exposition in several alkaline $\mathrm{pH}$. 


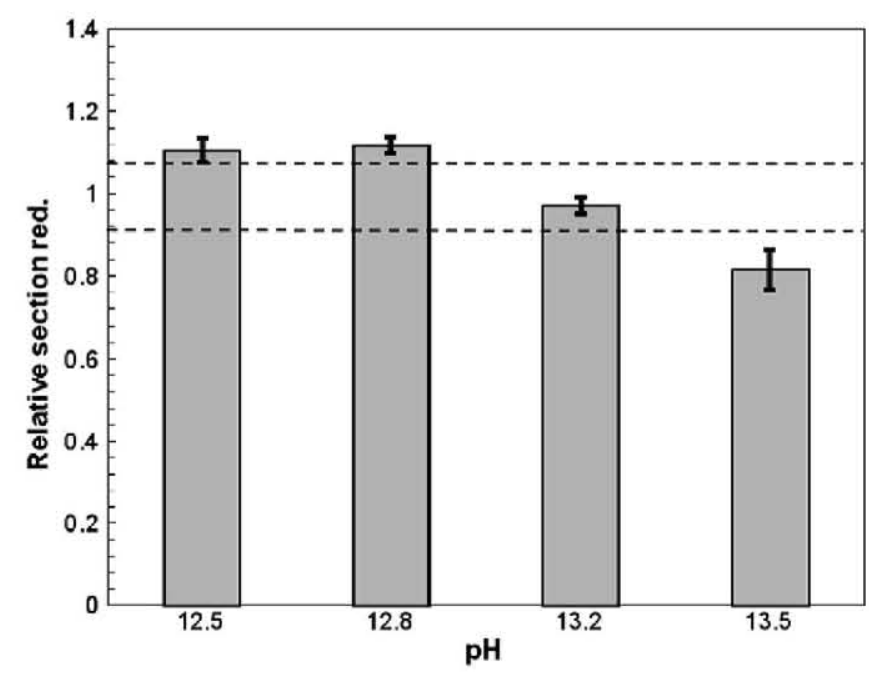

Fig. 7. Relative section reduction of $\mathrm{G} 1$ wires after $48 \mathrm{~h}$ of exposition in different alkaline media.

exposed to the most alkaline media (where the hydrogen evolution process takes place during all test) suffer HE and a simultaneous intensive galvanized coating reduction takes place. The repeatability represented in the figures in each testing conditions reflects the reproducibility of the phenomena.

The performance of full tendons ( $\mathrm{G} 2$ material) in contact with alkaline media was also considered. Reductions in the mechanical properties were found only in those tendons exposed at $\mathrm{pH} 13.5$ during $48 \mathrm{~h}$, in agreement with the results found with the isolated wires. In the case of tendons, the damage induced by hydrogen embrittlement process takes place mainly in the external wires but not in the central one. The failure by HE of a tendon is considered when one wire breaks under strain-stress tests.

The mechanical parameters analyzed have not shown clear signs of embrittlement in galvanized steel wires or tendons exposed to the lower $\mathrm{pH}$ media where the hydrogen evolution process not exceed $12 \mathrm{~h}(\mathrm{pH}: 12.5,12.8)$. This is indicative that the hydrogen amount generated in this case was not enough to affect the mechanical properties of the cold drawing steel. The wires exposed at $\mathrm{pH} 13.2$, which present a mean length time of hydrogen evolution process of $35 \pm 10 \mathrm{~h}$, are in the limit to suffer $\mathrm{HE}$, although this is not detected in the mechanical parameters of the wires. This behavior is attributed to two reasons:

(1) The amount of hydrogen generated at the coating surface is important but the hydrogen does not reach the bare steel. Therefore, the galvanized coating in this case was able to perform as an efficient barrier against hydrogen diffusion into the steel.

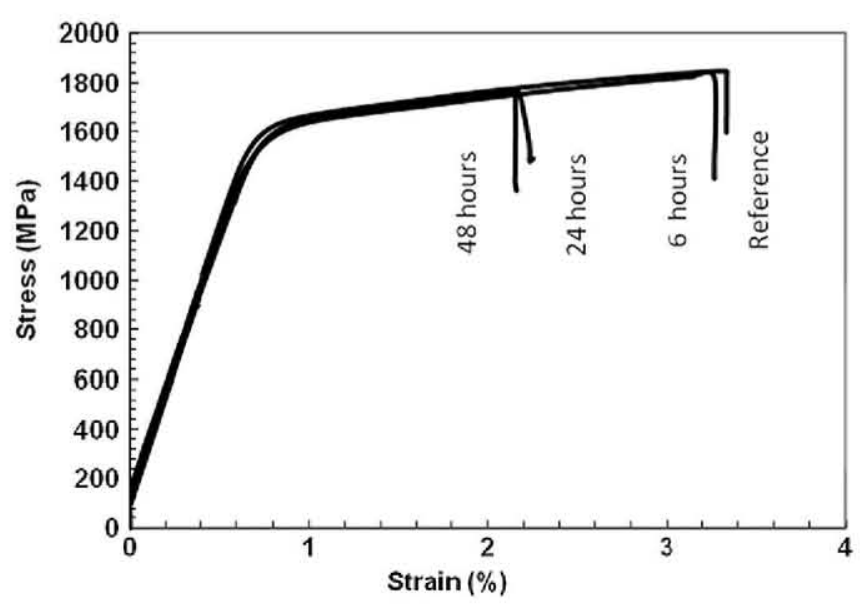

Fig. 8. SSRT in G2 tendons tested after several exposition times in the pH 13.5 .

(2) The amount of hydrogen diffused towards the bulk of the steel has not been sufficient to occlude inside the Fe latticed inducing embrittlement [19].

On the contrary, the galvanized steel exposed to $\mathrm{pH} 13.5$ (when the hydrogen evolution process was detected during whole test time), a clear decrease of strain in tensile test is detected. In these tests, a maximum strain ( $\varepsilon$ ) reduction of $30 \%$ was found. The explanation given is that during hydrogen evolution period an intensive attack of the galvanized coating occurs, decreasing its thickness and even completely consumed in local places, as shown in Fig. 4, so that higher content of hydrogen easily diffuses and enters the steel microstructure producing embrittlement of the steel.

In order to study the influence of the exposition time to the most alkaline media, SSRT was performed with tendons exposed at 6,24 and $48 \mathrm{~h}$. These results are shown in Fig. 8. After $6 \mathrm{~h}$ of exposure, a similar stress-strain curve to that of the reference is obtained. However the increase of exposition time to alkaline media induces an increase of hydrogen embrittlement risk. In both cases (24 and $48 \mathrm{~h}$ ) a reduction of $30 \%$ in the strain parameter was detected. This reduction of strain highlights an $\mathrm{H}$-induced embrittlement of the galvanized tendons in contact with alkaline environments.

The analysis of the fractures by SEM was performed in those samples where losses of ductility were detected. Fig. 9 shows an example of the reference fracture in air of a galvanized wire (Fig. 9-left), and a brittle fracture surface with lower necking and lower area reduction of a galvanized wire exposed to a $\mathrm{pH} 13.5$ over $48 \mathrm{~h}$ (Fig. 9-middle). Also a detailed analysis inside the fracture surface shows fracture zones with the formation of cleavage
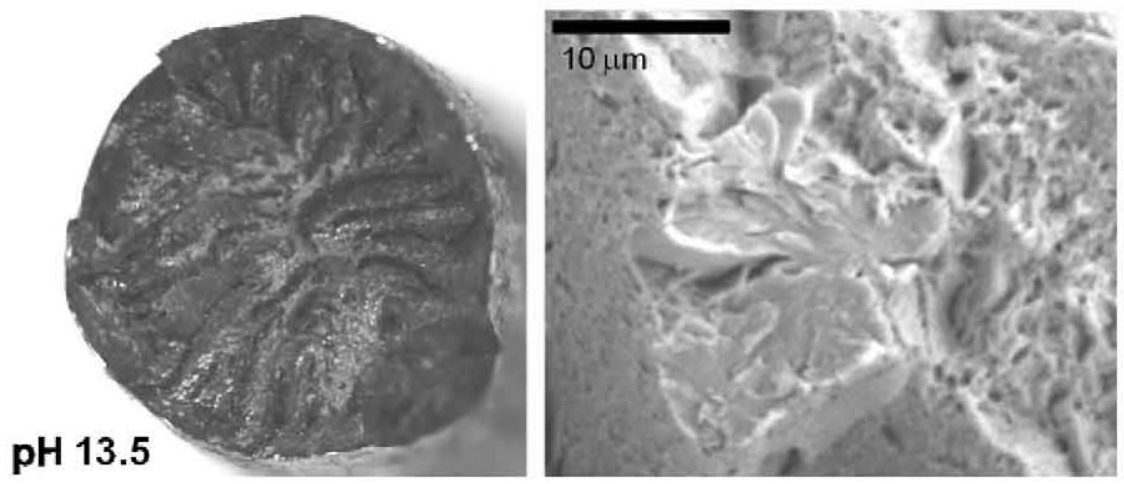

Fig. 9. SEM fracture observations of galvanized steel wire after $48 \mathrm{~h}$ at 13.5 and $80 \%$ load. (Left) general fracture, (right) detail in the brittle area. 

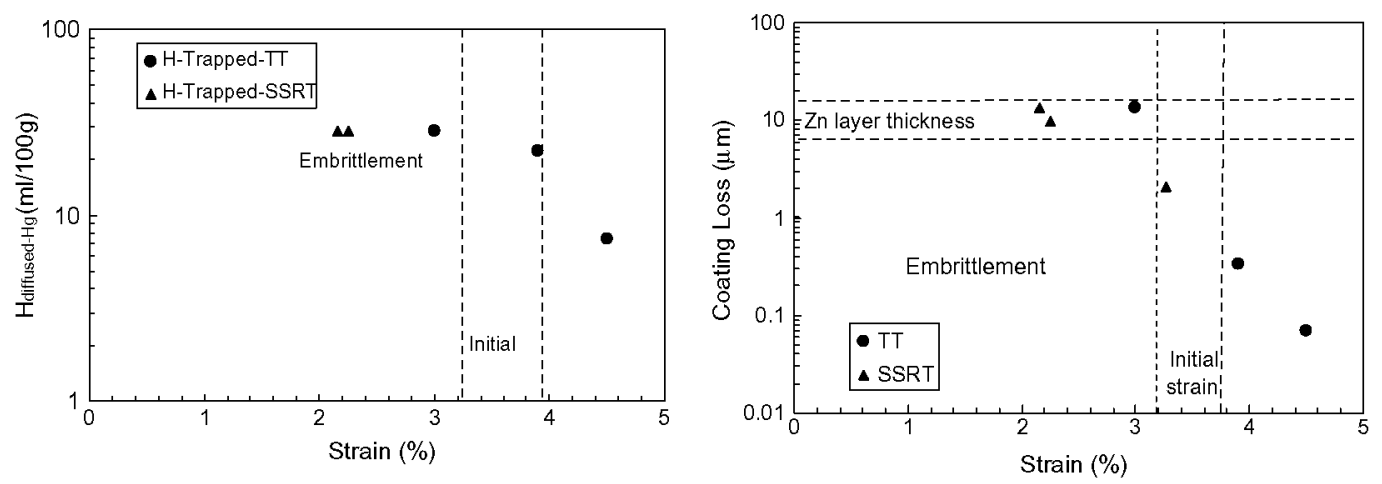

Fig. 10. Relation between hydrogen detected in galvanized steel (left) and $\mathrm{Zn}$ coating loss (right) with variation of the mechanical properties.

planes as those of Fig. 9-right, typically associated with hydrogen embrittlement phenomena $[33,34,36]$.

According to the results obtained in this study, a close relationship can be established between the corrosion processes taking place on the surface coating in contact with the alkaline environment (hydrogen evolution and $\mathrm{Zn}$ dissolution) and the mechanical properties. The amount of hydrogen accumulated inside the galvanized steel has a relationship with the mechanical properties losses in the wires, as shown in Fig. 10-left. In those cases that hydrogen has reached the bare steel and hydrogen embrittlement was detected ( $48 \mathrm{~h}$ in $\mathrm{pH} 13.5$ ) the hydrogen accumulated inside the galvanized steel was at least $30 \mathrm{ml}$ per $100 \mathrm{~g}$ of steel, inducing a mechanical strain reduction of $30 \%$. The high content of hydrogen accumulation is also accompanied by a reduction of around $75 \%$ in the thickness of the external $\mathrm{Zn}$ coating, as can be deduced from Fig. 10-right.

In the present study, it has been determined that $48 \mathrm{~h}$ of hydrogen evolution on the galvanized steel was needed to achieve hydrogen embrittlement process in the steel. However, the risk of suffering hydrogen embrittlement in real prestressed structures can be lower in because the hydrogen evolution period is limited to less than $8-10 \mathrm{~h}$, as reported in previous studies $[1,4]$. In fact, the kinetic of the corrosion process in galvanized prestressing steels is more limited due to the high electrical resistance offered by the concrete. The ohmic resistance progressively increases with the hardening of concrete just few hours after mixing.

\section{Conclusions}

1. HSGS in contact with alkaline environments induces two phenomena that act simultaneously: Active dissolution of the galvanized coating, and hydrogen evolution on the surface of the galvanized coating. These electrochemical reactions are intensified by the increase of $\mathrm{pH}$ (from 12.5 to 13.5 ). Also, the load applied in a prestressed structure in service ( $80 \%$ UTS) enhances both processes.

2. When hydrogen evolution takes place, part of this hydrogen is accumulated in the galvanized coating, acting as a barrier against the hydrogen diffusion towards the bare steel

3. Hydrogen embrittlement evidence has been found only in wires exposed to the higher alkaline media ( $\mathrm{pH} 13.5)$, where the hydrogen evolution process takes place throughout the entire test with high local losses of external $\eta$ layer.

\section{Acknowledgment}

The authors from CISDEM-CSIC wish to acknowledge the financial support received from the project BIA 2007-65394.

\section{References}

[1] M. Brachet, M.A. Raharinaivo, Des aciers à haute résistance, galvanisés, utilisables comme armatures de béton précontraint, Mat. Constr. 48 (1975) 323-327.

[2] P. Heiligenstaedt, K. Bohnenkamp, Investigations on the hydrogen-induced brittle fracture of galvanized prestressed steels in concrete, Arch. Eisenhüttenwes 47 (1976) 107-112.

[3] E. Riecke, Investigations on the influence of zinc on the corrosion behaviour of high strength steels, Mater. Corros. 30 (1979) 619-631.

[4] M. Brachet, M.A. Raharinaivo, Use of high strength hot-dip galvanized steel as prestressing tendons, in: FIP (Ed.), Proceedings of the 3rd Symposium of Federation International de la Précontrainte (FIP), Madrid, 1981, pp. 1-44.

[5] A.R. Cook, High strength galvanized steel wire in prestressed concrete. Galvanized reinforcement for concrete-II, in: ILZRO (Ed.): proceedings of the 12th international galvanizing conference, Paris, 1979, pp. 91-101.

[6] E. Riecke, B. Johnen, Hydrogen induced stress corrosion cracking of non galvanized and galvanized construction steels, Mater. Corros. 37 (1986) 310 317.

[7] P. Helene, M.F. Ferreira, P. Castro, Performance of 40-year old concrete bridge with embedded prestressed galvanized strands, Mater. Perform. (2004) $42-45$.

[8] A. Raharinaivo, Experimental Use of Galvanized Prestressing Steel for Stiffening the Roquemaure Bridge (France) by Additional Prestressing, in: Galvanized Reinforcement for Concrete - II, ILZRO report, Madrid, 1981, pp. 1-29.

[9] N.R. Short, S. Zhou, J.K. Dennis, Electrochemical studies on corrosion of a range of zinc alloy coated steel in alkaline solutions, Surf. Coat. Technol. 79 (1996) 218-224.

[10] C. Andrade, C. Alonso, Electrochemical aspects of galvanized reinforcement corrosion, in: S.R. Yeomans (Ed.), Galvanised steel reinforcement in concrete, Oxford, 2004, pp. 111-144.

[11] S.R. Yeomans, Galvanised steel reinforcement in concrete, Elsevier, Oxford, 2004. pp. 1-293.

[12] U. Nürnberger, Corrosion of metals in contact with mineral building materials, in: M. Raupach, B. Elsener, R. Polder, J. Mietz (Eds.), Corrosion Reinforcements in Concrete (EFC 38), EFC series, Belgium, 2006, pp. 1-336.

[13] J.A. González, G. Jáuregui, A.J. Vázquez, C. Andrade, Effect of coating structure on corrosion kinetics of galvanized reinforcement in concrete, Mater. Constr. 17 (1984) 409-414.

[14] l. Cornet, T. Ishikawa, B. Bresler, The mechanism of steel corrosion in concrete structures, Mat. Protect. 7 (1968) 44-47.

[15] J.A. González, R. Vargas, C. Andrade, Revisión sobre el comportamiento de las armaduras galvanizadas en el hormigón, Hormigón y Acero 124 (1977) 33132.

[16] K.W.J. Treadway, B.L. Brown, R.N. Cox, Durability of galvanized steel in concrete, in: Corrosion of reinforcing steel in concrete, ASTM STP 713 American Society of Testing and Materials, Philadelphia, 1980. pp. 102-131.

[17] T. Bellezze, M. Malavolta, A. Quaranta, N. Ruffini, G. Roventi, Cortosion behaviour in concrete of three differently galvanized steel bars, Cem. Concr. Comp. 28 (2006) 246-255.

[18] M. Pourbaix, Atlas of electrochemical equilibrium, Pergamon press, Oxford, 1996.

[19] M. Castellote, J. Fullea, P.G. de Viedma, C. Andrade, C. Alonso, I. Llorente, X Turrillas, J. Campo, J.S. Schweitzer, T. Spillane, R.A. Livinston, C. Rolfs, H.W. Becker, Hydrogen embrittlement steel submitted to slow strain rate studied by nuclear resonance reaction analysis and neutron diffraction, Nucl. Instrum. Methods B 259 (2007) 975-983.

[20] W. Lieber, Einfluß von zinkoxyd auf das erstarren und erhärtenvon portlandzementen, Zement-Kalk-Gips 3 (1967) 91-95.

[21] M.T. Blanco, C. Andrade, A. Macias, SEM study of the corrosion products of Galvanized Reinforcements immersed in Solutions in the pH Range 12.6 to 13.6, Br. Corros. J. 19 (1984) 41-48. 
[22] C. Andrade, J.A. Gonzalez, Quantitative measurements of corrosion rate of reinforcing steels embedded in concrete using polarisation resistance measurements, Werkst. Corros. 29 (1978) 515-519.

[23] A. Macias, C. Andrade, The behaviour of galvanized steel in chloride-containing alkaline solutions. I. The influence of the cation, Corros. Sci. 30 (1990) 393407.

[24] Z.Q. Tan, C.M. Hansson, Effect of surface condition on the initial corrosion of galvanized reinforcing steel embedded in concrete, Corros. Sci. 50 (2008) 2512-2522.

[25] Gaillet, L. Blondelle, Rapport d'étude nouveaux alliages de galvanisation, Lab. Central des Ponts et Chaussées, Internal Reference, GR000015363, Paris, 2005, p. 29.

[26] A.R. Marder, The metallurgy of zinc-coated steel, Prog. Mater. Sci. 45 (2000) 191-271.

[27] F. Porter, Zinc handbook: properties processing and use design, in: Marcel Decker. Inc., New York, 1991, p. 629.

[28] American Society for Metals, Handbook 13: Corrosion in: ASM International, Materials Park, USA, 1987, pp. 432-445.

[29] R.W. Sandelin, Galvanizing characteristics of different types of steel, Wire wire prod. (1940) $655-676$.
[30] A. Macias, C. Andrade, Corrosion of galvanized steel in dilute $\mathrm{Ca}(\mathrm{OH}) 2$ solutions (pH 11.1-12.6), Br. Corros. J. 22 (1987) 162-171.

[31] A. Macias, C. Andrade, Corrosion of galvanized steel reinforcements in alkaline solutions. Part 2: SEM study and identification of corrosion products, British. Corros. J. 22 (1987) 119-129.

[32] A. Macias, C. Andrade, Corrosion of galvanized steel reinforcements in alkaline solutions. Part 1: Electrochemical results, Br. Corros. J. 22 (1987) 113-118.

[33] G. Reumont, J.B. Vogt, A. lost, J. Foct, The effects of an intermetallic coating on the stress corrosion cracking behaviour of a hot-dip galvanized steel, Surf. Coat. Technol. 139 (2001) 265-271.

[34] Y. Yamaoca, H. Tsubono, M. Kurachi, Effect of galvanizing on hydrogen embrittlement of prestressing wire, PCl J. (1988) 146-158.

[35] A. Moragues, A. Macias, C. Andrade, Equilibria of chemical composition of the concrete pore solution. Part 1: Comparative of synthetic and extracted solutions, Cem. Concr. Res.17 (1987) 173-182.

[36] R. Roberge, W. Zheng, Hydrogen embrittlement susceptibility of galvanised 4135 steel in cement environment, Corros. Sci. 35 (1993) 507-514. 